\title{
Laparoscopic Resection of Calcifying Fibrous Pseudotumor of the Lower Posterior Mediastinum
}

\author{
S. Papachristos, MD, E. Chrysos, MD, S. Xenaki, MD, K. Lasithiotakis, MD, V. Haniotis, MD, \\ N. Asimakopoulou, MD, P. Papakonstantinou, MD, G. Chalkiadakis, MD \\ Department of General Surgery, University General Hospital of Heraklion, 71110 Heraklion, Crete Greece \\ (Drs. Papachristos, Chrysos, Xenaki, Lasithiotakis, Chalkiadakis). \\ Department of Pathology, Faculty of Medicine of Heraklion, 71110 Heraklion, Crete Greece \\ (Drs. Haniotis, Asimakopoulou, Papakonstantinou).
}

\begin{abstract}
Calcifying fibrous pseudotumor is a rare, benign, hypocellular tumor-like lesion that is characterized by the presence of dense hyalinized collagenous tissue interspersed with small spindle cells, dystrophic calcifications, or psammomatous and variable lymphoplasmacytic infiltrations. We report the case of a 37-year-old woman with a posterior mediastinal mass, in close contact with the distal third of the esophagus, treated by complete resection through a laparoscopic approach. The tumor had the histologic and immunohistochemical features of a calcifying fibrous pseudotumor.
\end{abstract}

Key Words: Calcifying fibrous pseudotumor, lower posterior mediastinum, laparoscopy, resection

Citation Papachristos S, Chrysos E, Xenaki S, Lasithiotakis K, Haniotis V, Asimakopoulou N, Papakonstantinou P, Chalkiadakis G. Laparoscopic resection of calcifying fibrous pseudotumor of the lower posterior mediastinum. CRSLS e2014.00161. DOI: 10.4293/CRSLS.2014.00161

Copyright $\odot 2014$ SLS This is an open-access article distributed under the terms of the Creative Commons Attribution-Noncommercial-ShareAlike 3.0 Unported license, which permits unrestricted noncommercial use, distribution, and reproduction in any medium, provided the original author and source are credited.

Disclosure statement: The authors have no conflicts of interest or financial ties to disclose.

Address correspondence to: Emmanuel Chrysos, MD, Department of General Surgery, University Hospital of Heraklion, 71110 Heraklion, Crete, Greece. E-mail manolischrysos@gmail.com, Telephone: +302810392676, Fax: +302810542063

\section{INTRODUCTION}

Calcifying fibrous pseudotumors (CFPs) are rare, benign tumor-like lesions characterized by the presence of small benign-appearing spindle cells in dense hyalinized collagenous tissue with focal and scattered lymphoplasmacytic infiltrations and focal dystrophic calcifications and/or psammoma bodies. These tumors were initially described in the subcutaneous and deep soft tissues of pediatric and young adult patients., ${ }^{1,2}$ Since then, various other anatomic locations have been reported. A review of the literature showed only 3 case reports of this lesion involving the mediastinum. ${ }^{3-5}$

We present the case of a tumor that developed over a period of 13 years in the posterior mediastinum of a 37-year-old woman. The tumor was laparoscopically resected, and the findings of the histologic examination were consistent with CFP.

\section{CASE REPORT}

A 37-year-old white woman visited our hospital after an incidental finding, on a routine chest radiograph, of a round well-defined mass in the left lower thoracic area, near the medial line and in contact with the left hemidiaphragm. She did not recall any symptoms such as retrosternal pain, nausea, weight loss, or poor appetite. A physical examination showed unremarkable findings. Her medical history was significant for a laparoscopic cholecystectomy 4 years ago and mild thalassemia. She denied any use of tobacco or alcohol and reported 2 natural births and a normal menstrual cycle. Her family history (firstdegree relatives) was unremarkable. Laboratory examinations showed only a mildly low hemoglobin level of 11.5 $\mathrm{g} / \mathrm{dL}$ (normal level, 12-16 g/dL). The serum levels of tumor markers were normal.

A thorough review of the patient's medical file showed a chest radiograph taken 13 years earlier that showed the same mass at the same location. A computed tomography scan of 
the chest showed a subrounded well-defined mass, $4 \mathrm{~cm}$ in diameter, at the lower posterior mediastinum, to the left of the descending thoracic aorta and in contact with the posterior wall of the peripheral third of the esophagus, just central to the gastroesophageal junction (Figures 1 and 2). The mass contained radiopaque foci, representing calcifications. No abnormally enlarged lymph nodes were observed. The radiologic differential diagnosis was leiomyoma of the esophagus or gastrointestinal stromal tumor and fibrolamellar carcinoma. The patient underwent further investigation with esophagogastroscopy, which showed only a small-degree transhiatal hernia.

We decided to use a laparoscopic approach for resection of the tumor. For laparoscopic resection of the tumor, 5 ports were used. The costal margin and xiphoid process were marked before pneumoperitoneum creation. The laparoscope was placed in a supraumbilical $10-\mathrm{mm}$ port. A 5-mm port for the surgeon's right hand was placed $3 \mathrm{~cm}$ below the xiphoid process. A 12-mm right lateral port for the liver retractor was placed $15 \mathrm{~cm}$ from the xiphoid process, 2 fingerbreadths below the right costal margin. A $10-\mathrm{mm}$ port for the assistant was placed $15 \mathrm{~cm}$ from the xiphoid process and 2 fingerbreadths below the left costal margin. A 12-mm port for the surgeon's left hand was finally placed $10 \mathrm{~cm}$ caudally to the $10-\mathrm{mm}$ assistant's port. The 12-mm port for the surgeon's left hand was used for the insertion of Harmonic scissors (Ethicon Endo-Surgery, Cincinnati, Ohio) (Figure 3).

After retraction of the left lobe of the liver to the right, with the liver retractor, we dissected the gastrohepatic ligament superior to the hepatic branch of the vagus nerve. Dissection of the gastrosplenic and gastrophrenic ligament with the use of Harmonic scissors, followed by mobilization of the lower-third part of the esophagus, allowed entrance to the posterior mediastinum, where the mass was found. The tumor was detached and dissected from the surrounding tissues with the use of Harmonic scissors.

The mass was located in the lower posterior mediastinum, in close contact but not infiltrating the esophagus. It was not inherent to any other anatomic structures.

Grossly, the tumor was well circumscribed and measured 6 $\mathrm{cm}$ in its greatest dimension. It was tan gray on cross sections and rubbery in consistency, and it contained foci of calcifications (Figure 4). Microscopically, the tumor was a benign hypocellular tumor, composed of small spindle cells in dense hyalinized collagenous tissue. No cellular atypia, mitotic activity, or necrosis was observed. There were scattered psammoma bodies, dystrophic calcifications (Figure 5), and focally, calcified ossification (Figure 6). There were also

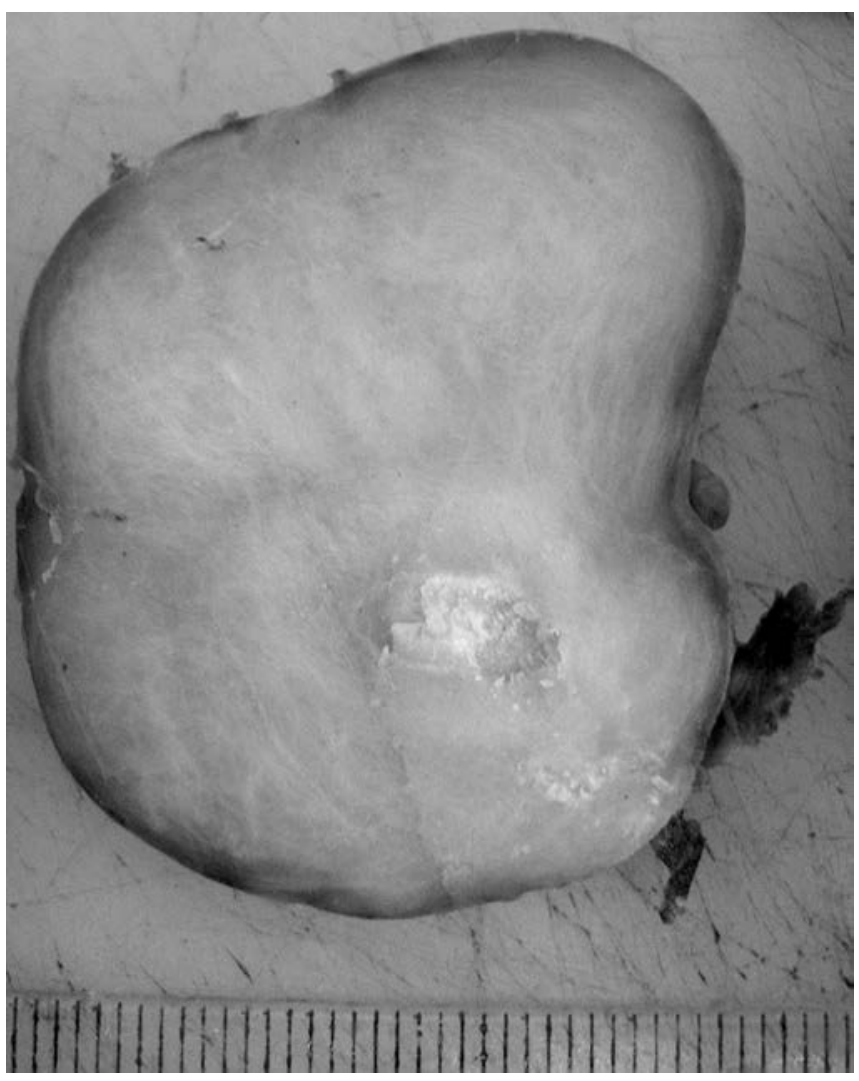

Figure 1. Macroscopical view of the tumor - Focal calcifications.

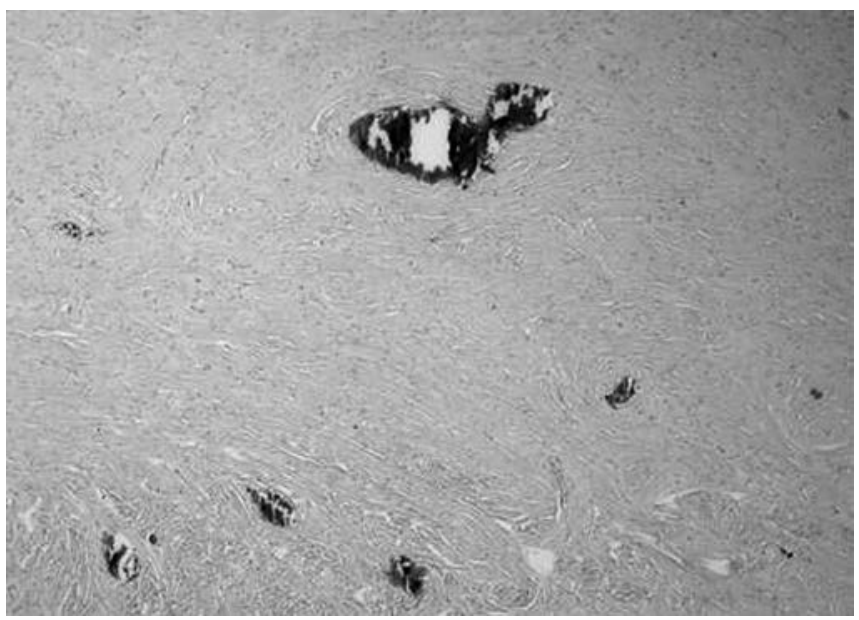

Figure 2. Dystrophic calcifications (hematoxylin-eosin stain, original magnification 40).

variable inflammatory infiltrations consisting of lymphocytes and plasma cells (Figure 7) and rare eosinophils. Few scattered mast cells were also recognized.

The immunohistochemical study included MNF-116, vimentin, actin, desmin, h-caldesmon, S-100, CD34, c-Kit 


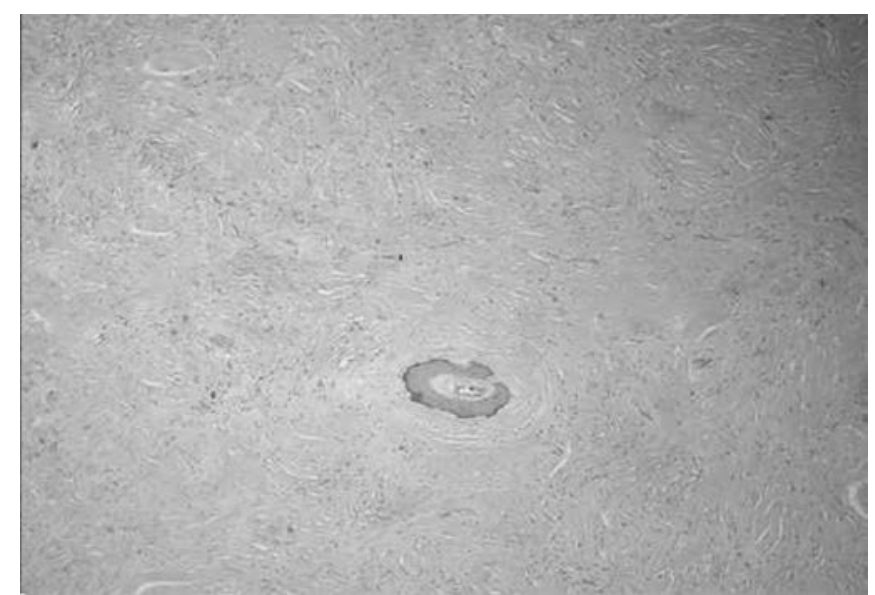

Figure 3. Calcified ossification (hematoxylin-eosin stain, original magnification 40).

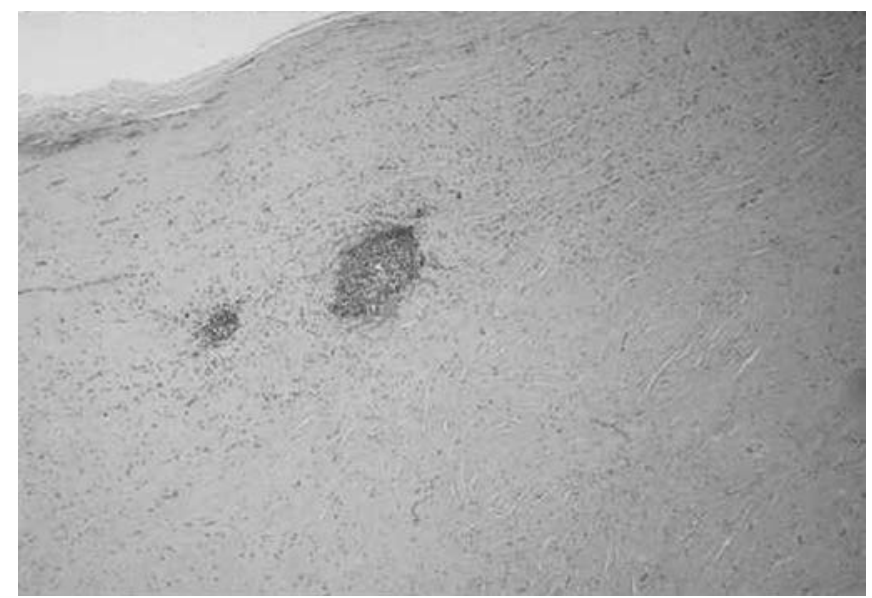

Figure 4. Focal lymphoplasmacytic infiltrations (hematoxylineosin stain, original magnification 40).

(CD117), bcl-2, ALK1, and Ki-67. The mitotic index of the small spindle cells by Ki-67 was negative. In addition, the immunohistochemical study showed positive expression only for vimentin (Figure 8) and was negative for the remainder of the primary antibodies. The combined histologic and immunohistochemical features of the tumor were consistent with a CFP.

After completion of the operation, approximation of the diaphragmatic crura was performed with 3 nonabsorbable sutures. Because the anterior aspect of the abdominal esophagus was not dissected free from the diaphragm and performed attachments, a fundoplication was not considered necessary. Because of the possibility of converting the procedure to a left thoracotomy, a double-lumen endotracheal tube was inserted preoperatively.

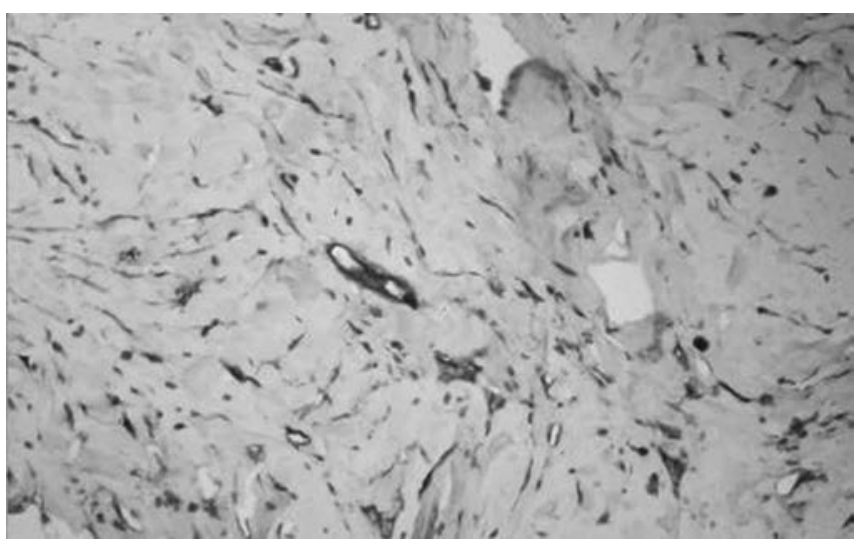

Figure 5. Positive expression of small spindle cells for vimentin (Immunohistochemical study - Vimentin (+), original magnification 200).

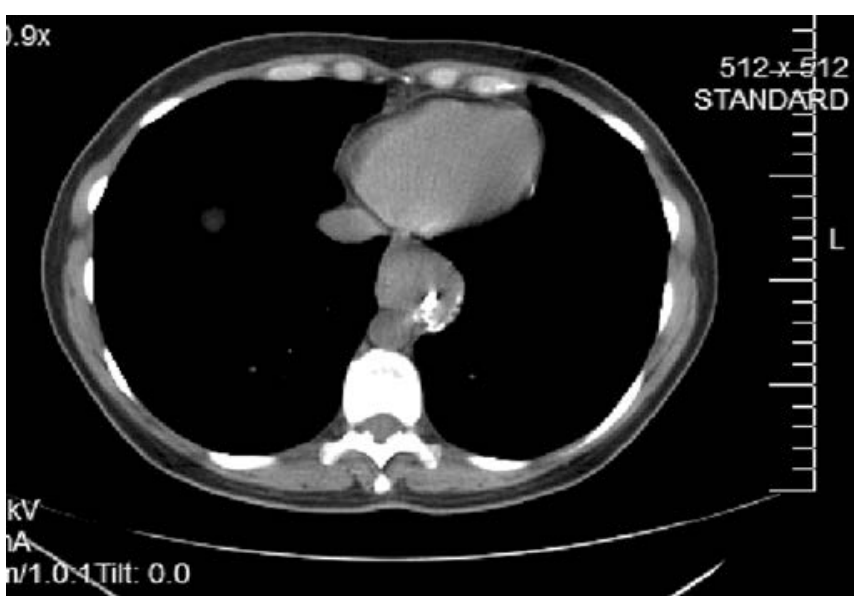

Figure 6. Chest CT scan, showing calcifying tumor on the posterior lower mediastinum.

The patient's postoperative course was uneventful, and she was discharged from the hospital on the fourth postoperative day. At her 6-month follow-up examination, she is symptom free with no clinical evidence of disease recurrence, phrenic nerve paralysis, or other postoperative complications.

\section{DISCUSSION}

CFP was originally described by Rosenthal et $\mathrm{al}^{1}$ in 1988. They called the lesion "childhood fibrous tumor with psammoma bodies." In 1993 Fetsch et al² renamed the entity "calcifying fibrous pseudotumor," emphasizing 3 important features: (1) the lesion is not limited to the pediatric population, (2) the calcifications are not always psammomatous, and (3) the tumor is the result of a reactive fibroinflammatory process. The exact 


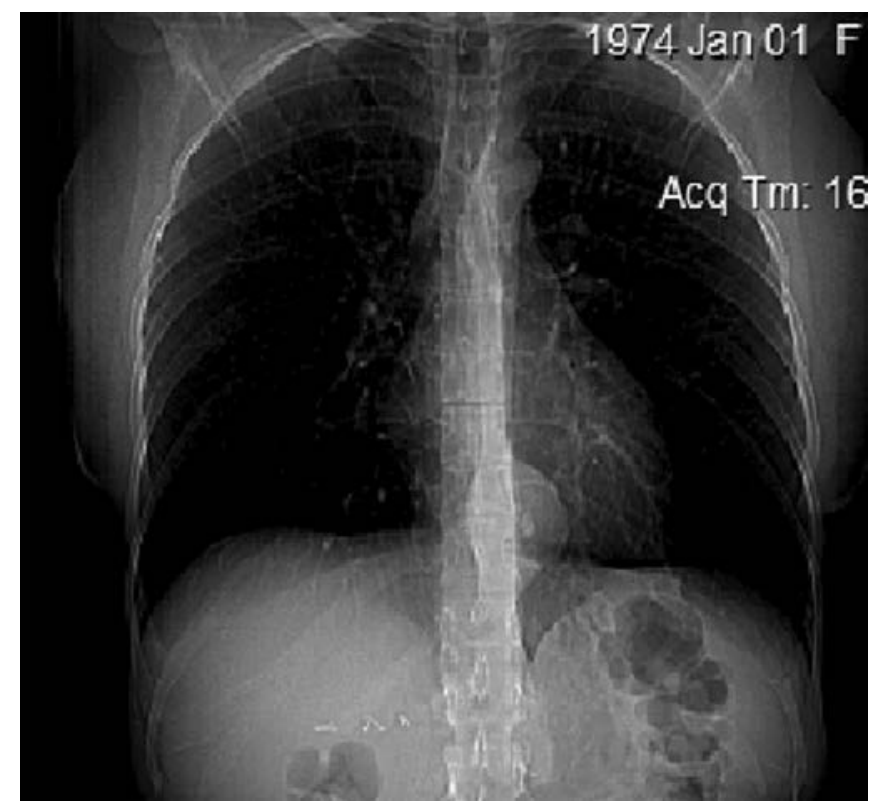

Figure 7. Chest CT scan, showing calcifying tumor on the posterior lower mediastinum.

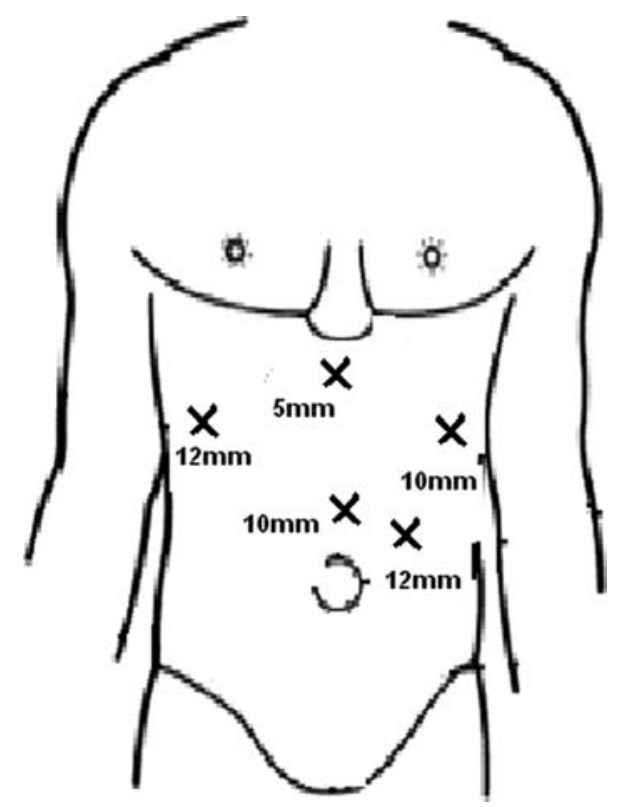

Figure 8. Placement of the ports.

pathogenesis of CFP remains unclear. It was originally hypothesized that CFP could be a sclerosing late stage of inflammatory myofibroblastic tumor, but several authors have reported no association between these 2 entities with regard to histologic, immunohistochemical, chromosomal abnormality, and electron microscopy characteristics. ${ }^{6-8}$
The differential diagnosis of CFP includes inflammatory myofibroblastic tumor, calcifying aponeurotic fibroma, fibromatosis, nodular fasciitis, and amyloidoma. For intra-abdominal tumors, the differential diagnosis includes retractile mesenteritis, inflammatory pseudotumor, smooth muscle tumor, pelvic or mesenteric fibromatosis, and omental elastofibroma. The previously mentioned lesions can be readily distinguished by histology and immunohistochemistry.?

Both sexes seem to be equally affected, and there is a wide age range, between 1 and 65 years, even though children and young adults are most frequently affected. ${ }^{10}$ The tumor size can vary from 0.6 to $25 \mathrm{~cm}$ in greatest dimension. ${ }^{7}$ The tumor has reported to have been present for 2 months to 13 years, which was the time in our case and is the longest reported in the literature. Calcifying fibrous tumors have recently been described in various anatomic locations such as the pleura, ${ }^{11-15}$ mesentery and peritoneum,,${ }^{7,16-20}$ stomach, ${ }^{21-23}$ adrenal glands, ${ }^{24}$ gingival and hard palate, ${ }^{10}$ soft palate, ${ }^{25}$ paratesticular and spermatic cord, ${ }^{7}$ lung, ${ }^{26}$ myocardium, ${ }^{27}$ esophagus, ${ }^{28}$ and liver. ${ }^{29}$ Malignant transformation has not been reported so far. Surgical resection with a margin of normal tissue is curative, even though some extremely rare cases of recurrence have been reported. Fetsch et $\mathrm{al}^{2}$ reported 1 case of recurrence that became clinically apparent 7.5 years after resection. Maeda et al ${ }^{30}$ and Nascimento et $\mathrm{al}^{7}$ report 3 recurrences each. One recurrence was noted on the submandibular gland of a female patient 4 months after incomplete removal of the primary tumor. The histologic features of the recurrence were similar to those of the primary lesion. ${ }^{8}$ Although recurrence after resection of a CFP is rare, the prevalence of recurrence in relation to the anatomic location, hormonal status, age, and sex remains to be determined.

In our patient, the laparoscopic approach was chosen over thoracoscopy because of the lower position of the mass in the posterior mediastinum, in case mobilization of the abdominal esophagus and stomach was necessary. Ro (removal of all tumor with microscopic examination of margins showing no tumor cells) resection was feasible, and in the event of an esophageal perforation at this level, which is a possibility, such a perforation would be easily repaired without the need for a thoracotomy. Finally, and most importantly, if the muscular layer of the esophagus is infiltrated by the tumor, it should be resected with the mass; in this case an antireflux procedure would be readily added through the laparoscopy. 
All of the previously mentioned reasons, along with the fact that postoperative pain is reduced because there is no need for a chest tube, make the laparoscopic approach the best choice. Possible complications and danger points need to be expected, and an experienced team that is able to manage them needs to be available. These include esophageal perforation, phrenic and vagus nerve injury, injury to the azygos vein, superior vena cava or thoracic aorta injury, herniation of viscera through the hiatal opening, and tension pneumothorax due to unrecognized entry into the mediastinal pleura.

Our case appears to be the first laparoscopic excision of a CFP in the posterior lower mediastinum. Two other laparoscopic approaches have been reported in the past, for the resection of a CFP on the anterior parietal peritoneum, by Konstantakos and Shuck, ${ }^{16}$ and the lesser curvature of the gastric wall, by Attila et al. ${ }^{21}$

To date, the treatment of choice for CFP is complete surgical excision, although therapeutic recommendations have not yet been established because of the relatively small number of cases. Our case report is the first description of a laparoscopically resected CFP of the posterior mediastinum; it stresses the usefulness and effectiveness of such an approach for the complete treatment of a CFP located in the posterior mediastinum.

\section{References:}

1. Rosenthal NS, Abdul-Karim FW. Childhood fibrous tumor with psammoma bodies. Arch Pathol Lab Med. 1988;112(8):798-800.

2. Fetsch JF, Montgomery EA, Meis JM. Calcifying fibrous pseudotumor. Am J Surg Pathol. 1993;17(5):502-508.

3. Dumont P, de Muret A, Skrobala D, Robin P, Toumieux B. Calcifying fibrous pseudotumor of the mediastinum. Ann Thorac Surg. 1997;63(2):543-544.

4. Jeong HS, Lee GK, Sung R, Ahn JH, Song HG. Calcifying fibrous pseudotumor of mediastinum-a case report. J Korean Med Sci. 1997;12(1):58-62.

5. Hsieh SC. Calcifying fibrous pseudotumor of the mediastinum. Ann Acad Med. 2011;40:152-153.

6. Sigel JE, Smith TA, Reith JD, Goldblum JR. Immunohistochemical analysis of anaplastic lymphoma kinase expression in deep soft tissue calcifying fibrous pseudotumor: evidence of a late sclerosing stage of inflammatory myofibroblastic tumor? Ann Diagn Pathol. 2001;5(1):10-14.

7. Nascimento AF, Ruiz R, Hornick JL, Fletcher CD. Calcifying fibrous 'pseudotumor': clinicopathologic study of 15 cases and analysis of its relationship to inflammatory myofibroblastic tumor. Int J Surg Pathol. 2002;10(3):189-196.
8. Hill KA, Gonzalez-Crussi F, Chou PM. Calcifying fibrous pseudotumor versus inflammatory myofibroblastic tumor: a histological and immunohistochemical comparison. Mod Pathol. 2001;14(8):784-790

9. Weiss SW, Goldblum JR. Calcifying fibrous pseudotumor. In: Enzinger and Weiss's Soft Tissue Tumors. 5th ed. St Louis: Mosby; 2008:294-297.

10. Bell DM, Dekmezian RH, Husain SA, Luna MA. Oral calcifying fibrous pseudotumor: case analysis and review. Head Neck Pathol. 2008;2(4):343-347.

11. Hainaut P, Lesage V, Weynand B, Coche E, Noirhomme P. Calcifying fibrous pseudotumor (CFPT): a patient presenting with multiple pleural lesions. Acta Clin Belg. 1999;54(3):162164 .

12. Pinkard NB, Wilson RW, Lawless N, et al. Calcifying fibrous pseudotumor of pleura. A report of three cases of a newly described entity involving the pleura. Am J Clin Pathol. 1996; 105(2):189-194.

13. Mito K, Kashima K, Daa T, et al. Multiple calcifying fibrous tumors of the pleura. Virchows Arch. 2005;446(1):78-81.

14. Jang KS, Oh YH, Han HX, et al. Calcifying fibrous pseudotumor of the pleura. Ann Thorac Surg. 2004;78(6):e87-e88.

15. Shibata K, Yuki D, Sakata K. Multiple calcifying fibrous pseudotumors disseminated in the pleura. Ann Thorac Surg. 2008;85(2):e3-e5.

16. Konstantakos AK, Shuck JM. Calcifying fibrous pseudotumor of the anterior parietal peritoneum: treatment by laparoscopic resection. Surgery. 2005;137(2):257-259.

17. Ben-Izhak O, Itin L, Feuchtwanger Z, Lifschitz-Mercer B, Czernobilsky B. Calcifying fibrous pseudotumor of mesentery presenting with acute peritonitis: case report with immunohistochemical study and review of literature. Int J Surg Pathol. 2001;9(3):249-253.

18. Kocova L, Michal M, Sulc M, Zamecnik M. Calcifying fibrous pseudotumour of visceral peritoneum. Histopathology. 1997; 31(2):182-184.

19. Weynand B, Draguet AP, Bernard P, Marbaix E, Galant C. Calcifying fibrous pseudotumour: first case report in the peritoneum with immunostaining for CD34. Histopathology. 1999; 34(1):86-87.

20. Chen KT. Familial peritoneal multifocal calcifying fibrous tumor. Am J Clin Pathol. 2003;119(6):811-815.

21. Attila T, Chen D, Gardiner GW, Ptak TW, Marcon NE. Gastric calcifying fibrous tumor. Can J Gastroenterol. 2006;20(7):487-489.

22. Delbecque K, Legrand M, Boniver J, Lauwers GY, de Leval L. Calcifying fibrous tumour of the gastric wall. Histopathology. 2004;44(4):399-400. 
23. Puccio F, Solazzo M, Marciano P, Benzi F. Laparoscopic resection of calcifying fibrous pseudotumor of the gastric wall. A unique case report. Surg Endosc. 2001;15(10):1227.

24. Eftekhari F, Ater JL, Ayala AG, Czerniak BA. Case report: calcifying fibrous pseudotumour of the adrenal gland. $\mathrm{Br} \mathrm{J} \mathrm{Ra-}$ diol. 2001;74(881):452-454.

25. Mardi K, Sharma J. Calcifying fibrous pseudotumor of the soft palate-a case report. Indian J Pathol Microbiol. 2006; 49(3):394-395.

26. Soyer T, Ciftci AO, Güçer S, Orhan D, Senocak ME. Calcifying fibrous pseudotumor of lung: a previously unreported entity. J Pediatr Surg. 2004;39(11):1729-1730.
27. Kirby PA, Sato Y, Tannous R, Dehner LP. Calcifying fibrous pseudotumor of the myocardium. Pediatr Dev Pathol. 2006;9(5):384-387.

28. Lee SW, Yeh HZ, Chang CS. Calcifying fibrous pseudotumor of the esophagus. J Chin Med Assoc. 2010;73(11):599601.

29. Nobili C, Rosso E, Oussoultzoglou E, Casnedi S, Jaeck D, Bachellier P. Image of the month. Hepatic calcifying fibrous pseudotumor. Arch Surg. 2011;146(2):237-238.

30. Maeda A, Kawabata K, Kusuzaki K. Rapid recurrence of calcifying fibrous pseudotumor (a case report). Anticancer Res. 2002;22(3):1795-1797. 